\title{
Seprase; an overview of an important matrix serine protease
}

Pamela O’Brien ${ }^{\mathrm{a}}{ }^{*}$ and Brendan F. O’Connor ${ }^{\mathrm{ab}}$

${ }^{\text {a }}$ School of Biotechnology, Dublin City University, Dublin 9, Ireland.

${ }^{\mathrm{b}}$ Centre for BioAnalytical Sciences, Dublin City University, Dublin 9, Ireland.

\section{* CORRESPONDENCE}

${ }^{*}$ Corresponding author for proofs:

Pamela O’Brien, School Of Biotechnology, Dublin City University, Dublin 9, Ireland.

Email address: pamelaobrien4@gmail.com

Phone: $+353-1-7005908 \quad$ Fax: $+353-1-7005412$

\section{KEYWORDS (6)}

Seprase; Fibroblast Activation Protein alpha; Serine peptidase; Antiplasmin Cleaving Enzyme; Serine Integral Membrane Protein

\section{ABBREVIATIONS}

AEBSF, 4-(2-aminoethyl)-benzenesulfonyl fluoride; AFC, 7-amino-4trifluoromethylcoumarin; AMC, 7-amino-4-methylcoumarin; APSF, 4-amidino phenylsulfonyl fluoride; DABCYL, 4-(4-dimethylaminophenylazo)benzoyl; DFP, Diisopropyl fluorophosphates; DPPIV, Dipeptidyl peptidase IV; DTT, Dithiothreitol; ECM, Extracellular matrix; EDANS, 5-[(2-aminoethyl)amino]-naphthalene-1-sulfonic acid; EDTA, Ethylenediaminetetra acetic acid; FGF-2, Fibroblast growth factor-2; GBase, Guanidinobutyrase; MMP, Matrix metallo-proteinase; mAb, monoclonal antibody; NEM, N-ethylmaleimide; PMSF, Phenylmethylsulphonyl fluoride; POP, Prolyl Oligopeptidase; SIMP, Serine Integral Membrane Protein; uPA, Urokinase plasminogen activator 


\begin{abstract}
Seprase or Fibroblast activation protein (FAP) is an integral membrane serine peptidase, which has been shown to have gelatinase activity. Seprase has a dual function in tumour progression. The proteolytic activity of Seprase has been shown to promote cell invasiveness towards the ECM and also to support tumour growth and proliferation. Seprase appears to act as a proteolytically active $170-\mathrm{kDa}$ dimer, consisting of two $97-\mathrm{kDa}$ subunits. It is a member of the group type II integral serine proteases, which include dipeptidyl peptidase IV (DPPIV/CD26) and related type II trans-membrane prolyl serine peptidases, which exert their mechanisms of action on the cell surface. DPPIV and Seprase exhibit multiple functions due to their abilities to form complexes with each other and to interact with other membrane-associated molecules. Localization of these protease complexes at cell surface protrusions, called invadopodia, may have a prominent role in processing soluble factors and in the degradation of extracellular matrix components that are essential to the cellular migration and matrix invasion that occur during tumour invasion, metastasis and angiogenesis.
\end{abstract}




\section{Introduction}

Wound healing and tumour development are dynamic progressive processes that involve the interaction of several tissue types and have many mechanistic similarities. The composition of tumour stroma markedly resembles that of wound granulation tissue, although a distinguishing feature of the tumour stroma is the absence of platelets and a lower density of inflammatory cells [1]. In cancer, these changes in the stroma drive invasion and metastasis, the hallmarks of malignancy (Fig. 1.). Tumour cells can produce many of the same growth factors that activate the adjacent stromal tissues as in wounding or fibrosis. Activated fibroblasts and infiltrating immune cells (macrophages) secrete proteases (MMPs) and cytokines such as Fibroblast Growth Factor-2 (FGF-2). These factors potentiate tumour growth, stimulate angiogenesis and induce fibroblasts to undergo differentiation into myofibroblasts and into smooth muscle [2].

Cell surface proteases play an important role in facilitating cell invasion into the extracellular matrix. Proteases associate at plasma membrane protrusions, called invadopodia, which contact and dissolve the matrix. Invadopodia degrade a variety of immobilised substrates including fibronectin, laminin and type I collagen [3]. Integral membrane proteases may contribute significantly to ECM degradation by metastatic cells by virtue of their localisation at invadopodia which are in contact with the ECM. Integral membrane proteases can be defined as a group of cell surface glycoproteins that contain extracellular domains of either metallo- or serine-proteases, a transmembrane domain and a short cytoplasmic tail. Examples of such transmembrane glycoproteins include meprin, matrix metalloproteinase, DPPIV, 
fibroblast activation protein $\alpha(\mathrm{FAP} \alpha)$ / Seprase and GBase. Abundant expression of these enzymes is associated with poor prognosis [4].

This review will take a detailed look at the serine protease Seprase (surface expressed protease) or Fibroblast Activation Protein $\alpha$ (FAP $\alpha)$, a 170kDa integral membrane gelatinase, which belongs to the S9b peptidase family [5, 6]. FAP $\alpha$, formerly known as F19 Cell Surface Antigen, is an inducible cell surface glycoprotein that was originally identified in 1986 in cultured fibroblasts using the monoclonal antibody (mAb) F19 [7-9][7, 8]. In the early years using the mAb F19, malignant epithelial cancers such as breast, lung, colon and ovarian were found to be F19 . In 1994, the F19 Cell Surface Antigen was named Fibroblast Activation Protein $\alpha(F A P \alpha)$. In 1990 a $170 \mathrm{kDa}$ gelatinase was identified in the human malignant melanoma cell line LOX . The 170kDa membrane-bound protease was found to be associated with the expression of invasiveness by human malignant melanoma cells. In 1994, the 170kDa gelatinase was named Seprase . Seprase was originally identified as a glycoprotein peptidase selectively expressed on the surface of invadopodia and was isolated from a human malignant melanoma cell line LOX [3, 12][9]. The expression of Seprase correlates with the invasiveness of human melanoma and carcinoma cells [12][9]. Using anti-Seprase mAbs, Seprase was seen to be expressed in stromal fibroblasts of more than $90 \%$ of all epithelial tumours including lung, colorectal and breast carcinomas (primary and metastatic) . Molecular cloning of both FAP $\alpha$ and Seprase revealed that they are the same cell surface serine protease which is found on chromosome 2q23 [12-16][9-13]. The fact that FAP $\alpha$ and Seprase are the same protease means that the above immunohistochemistry results contradict each other. The reason for the differing results is due to the different monoclonal antibodies 
recognising different parts of the serine protease. For the clarity of this review, the protease is referred to as Seprase throughout.

\section{Classification of Seprase / Fibroblast Activation Protein alpha (FAP $)$}

Seprase (EC 3.4.21.B28) belongs to the small family of serine integral membrane peptidases (SIMPs). These peptidases are inducible, specific for proline-containing peptides and macromolecules and active on the cell surface [15]. Post proline peptidases modify bioactive peptides and change their cellular functions. This class of peptidases have important roles in cancer [14, 15, 17-19]. This group of enzymes also includes prolyl endopeptidase, dipeptidyl peptidase 8 and dipeptidyl peptidase IV- $\beta$ [19]. However, the best studied of this class of enzymes is dipeptidyl peptidase IV (DPPIV or CD26) (EC 3.4.14.5) [19]. Studies have shown the importance of DPPIV in regulating tumour cell behaviour and function [20]. Seprase shows up to $52 \%$ homology to DPPIV, both being members of the S9b peptidase family [21]. Seprase is, therefore, a member of the DPPIV-like gene family [5] grouped in the subfamily S9b of the peptidase family S9 (prolyl oligopeptidase family), clan SC [6]. Even though all SIMP members are known to cleave prolyl peptide (Pro-Xaa) bonds there

are conflicting reports on possible dipeptidyl peptidase activity associated with Seprase but its main distinguishing feature is its gelatinase activity [22, 23]. An early report had suggested that DPPIV had gelatinase activity [24]. However, more recent reports suggest otherwise $[22,23]$. The exact nature of the physiological roles Seprase plays are only beginning to be understood but insights into potential functions of Seprase can be obtained from the vast amount of work done on DPPIV. 
$-6-$ 


\section{Structure and Biochemical Aspects}

Active Seprase is a $170 \mathrm{kDa}$ homodimer that contains two $\mathrm{N}$-glycosylated $97 \mathrm{kDa}$ subunits. The 760 amino acid Seprase protein (GenBank GI 1888316) is a type II integral membrane protein with a large C-terminal extracellular domain. Seprase has been shown to shed from the cell surface and recent studies by our group have identified a serum form of the protease [25][22]. A second group has recently identified the soluble form of Antiplasmin Cleaving Enzyme (APCE) as Seprase $[26][23]$.

The Seprase monomer has 5 potential N-glycosylation sites, 13 cysteine residues, 3 segments that correspond to highly conserved catalytic domains of serine proteases, a hydrophobic transmembrane segment and a short cytoplasmic tail (6 amino acids) (Fig. 1. ref [14][11]). The crystal structure of the extracellular domain of Seprase has recently been resolved (Fig. 2.) [27][24]. This has provided valuable information on the substrate specificity of Seprase (discussed further in this Section and also in Section 7.).

Each subunit contains topologically distinct domains: the $\beta$-propeller (residues 54492) and the $\alpha / \beta$-hydrolase domain (residues $27-53$ and 493-760) (Fig. 2.). The catalytic triad is located at the interface of the $\beta$-propeller and the $\alpha / \beta$-hydrolase domain. The arrangement of the catalytic triad in the order nucleophile-acid-base is a characteristic of the $\alpha / \beta$ hydrolase domain [28][25]. This domain features mostly parallel $\beta$-sheets connected by $\alpha$-helices on either surface of the sheet (Fig. 3A.). The sheets are twisted and radially arranged around their ventral tunnel. The eight bladed $\beta$-propeller domain is situated on top of the catalytic triad and may serve as a 'gate' to 
selectively filter protein access to the catalytic triad (Fig. 3B.) $[27,29][24,26]$. The $\beta-$ propeller domain in Prolyl Oligopeptidase has been shown to regulate proteolysis [30][27]. The oscillating propeller blades have been shown to act as a gating filter during catalysis, letting small peptide substrates into the active site while excluding large proteins to prevent accidental proteolysis in the cytosol. The active site is accessible in two ways; (i) through a cavity formed between the $\beta$-propeller and (ii) through the hydrolase domain. The side opening has a diameter of $\sim 24 \AA$ in contrast to the narrower $\beta$-propeller opening $(\sim 14 \AA)$.

As mentioned earlier, DPPIV shows similar structure homology to Seprase. In DPPIV, the N-terminal hydrophobic sequence represents an uncleavable signal peptide, that also functions as a membrane-anchoring domain $[6,31][6,28]$. In Seprase, the N-terminal domain possibly has a similar role as a signal peptide, although there is no published data to support this. A highly conserved residue Asp ${ }^{599}$ in DPPIV has been shown to be important in enzyme processing such as proper folding, dimerisation and transport [15][12]. A mutation in this residue (D599A) specifically decreased the cell surface expression of DPPIV in stably transfected mouse fibroblasts. Seprase also has this conserved $\mathrm{Asp}^{599}$ residue (Fig. 4.); therefore, it is possible to conclude that this residue is also important in the processing of the Seprase enzyme.

The Seprase gene has been observed in several species (Fig. 4.). A mouse homologue has been identified [32][29] as well as a Xenopus laevis homologue [33][30]. The mouse Seprase gene spans approximately $60 \mathrm{~kb}$ and contains 26 exons ranging in size from $46 \mathrm{bp}$ to $195 \mathrm{bp}$. This genomic organisation is similar to that of the human 
Seprase gene [32]. The catalytic serine residue arranged within the consensus sequence G-X-S-X-G is split between two exons. Gly-Trp is located at the very end of exon 21 and Ser-Tyr-Gly at the beginning of exon 22 (discussed further in Section 3.1.). This arrangement differs from the typical serine protease where the complete serine consensus site is encoded within one exon. The study of the mouse homologue has shown alternative splicing and 3 distinct Seprase splice variants have been detected in tissues [34][31]. An alternative spliced Seprase was later identified in the human melanoma cell line LOX which encodes a novel truncated isoform [35][32]. The splice variant encodes for a 239 amino acid polypeptide with a molecular weight of $27 \mathrm{kDa}$ that precisely overlaps the carboxyl-terminal catalytic region of the wild type Seprase. An alignment of eukaryotic Seprase C-terminal amino acid sequences is shown in Fig. 4. Sequence homology is represented in grey scale shading, with black being the highest homology. This figure also illustrates that the C-terminal catalytic region of Seprase is highly homologous throughout the different species.

The charged N-terminal end of substrate peptides is recognised by two glutamates (Glu motif). Comparison of the crystal structure of Seprase and DPPIV revealed one major difference in the vicinity of the Glu motif $\left(\mathrm{Glu}^{203}-\mathrm{Glu}^{204}\right.$ for Seprase; Glu ${ }^{205}$ $\mathrm{Glu}^{206}$ for DPPIV) within the active site of the enzyme (Fig. 2. ref [27][24]). The importance of the Glu motif in DPPIV catalysis has been confirmed by single-point mutations that abolish the enzymes aminopeptidase activity [36][33]. Detailed comparison of Seprase and DPPIV revealed that the Ala ${ }^{657}$ residue in Seprase, instead of $\mathrm{Asp}^{663}$ as in DPPIV, reduces the acidity in this pocket. This change could explain the lower affinity for N-terminal amines by Seprase [27][24]. Mutant proteins were developed to determine the importance of these two residues. Studies have shown that 
in DPPIV, the replacement of $\mathrm{Asp}^{663}$ by an alanine Ala ${ }^{663}$ results in a $\sim 4$-fold decrease in catalytic efficiency for $\mathrm{N}$-terminal dipeptides, with a concomitant increase in efficiency to cleave Z-Gly-Pro-AMC (which has been shown to be cleaved by DPPIV). This mutation caused the wild type DPPIV catalytic efficiency for Z-GlyPro-AMC to be increased from $9 \mathrm{M}^{-1} \mathrm{~s}^{-1}$ to $1.6 \mathrm{M}^{-1} \mathrm{~s}^{-1}$.

Structural composition of the active sites of Seprase and DPPIV revealed similar $\mathrm{S}_{2}$ $\mathrm{S}_{2}{ }^{\prime}$ specificity pockets. The $\mathrm{S}_{1}$ ' subsite (numbered according to [37][34]) in Seprase is flat and could accommodate most amino acids. The $\mathrm{S}_{2}$ ' active site pocket is lined by $\operatorname{Trp}^{623}$ and $\mathrm{Tyr}^{745}$. These residues would be expected to interact with large aliphatic side chains of peptide substrates. The $\mathrm{S}_{1}$ specificity pocket in Seprase is a well defined hydrophobic pocket lined by $\mathrm{Tyr}^{625}, \mathrm{Val}^{650}, \mathrm{Trp}^{653}, \mathrm{Tyr}^{656}, \mathrm{Tyr}^{660}$ and $\mathrm{Val}^{705}$. This site optimally accommodates a proline residue. Large hydrophobic and aromatic residues can be modelled in the hydrophobic $\mathrm{S}_{2}$ pocket, defined by residues $\mathrm{Arg}^{123}$, $\mathrm{Phe}^{350}$, $\mathrm{Phe}^{351}, \mathrm{Tyr}^{541}, \mathrm{Pro}^{544}, \mathrm{Tyr}^{625}$ and $\mathrm{Tyr}^{660}[27][24]$.

\subsection{Catalytic Classification}

In its membrane form, the majority of Seprase including its catalytic domain is exposed to the extracellular environment (Fig. 1. ref [14][11]). The catalytic domain consists of the catalytic serine (S624) flanked by glycines in the classical consensus sequence for an active site serine, G-X-S-X-G. This conserved serine protease motif is present as G-W-S-Y-G. The catalytic serine in conjunction with $\mathrm{Asp}^{702}$ and His ${ }^{734}$ comprises the catalytic triad $[12,16,21][9,13,18]$. The orientation of these residues is similar to members of the prolyl oligopeptidase family and its structural organisation is similar to that of DPPIV. Therefore, this enzyme is classified as a non- 
classical serine protease. An interesting observation made in DPPIV is that a single substitution of either Gly residue in the motif resulted in the retention of the newly synthesised enzyme in the endoplasmic reticulum and rapid degradation [6]. This suggests that both residues are also essential for correct folding of the enzyme and transport to the cell surface. The histidine acts as a general acid-base catalyst activating the nucleophilic group, the hydroxyl group of the serine acts as a nucleophile in the attack on the peptide bond while the aspartic acid stabilises charged tetrahedral intermediates formed in the reaction $[38,39][35,36]$.

\subsection{Biochemical Properties of Seprase}

Post translational modifications of the Seprase protein such as N-glycosylation occurs and it is thought that the N-terminus may be blocked [12]. The resolved crystal structure of Seprase shows that there are 5 potential glycosylation sites on the asparagine residues 49, 92, 227, 314 and 679. Four are located in the $\beta$-propeller domain and one is located in the hydrolase domain [27]. The glycosylated form of Seprase has both post-prolyl dipeptidyl peptidase and gelatinase activities while the non-glycosylated form lacks any detectable activity [40][37].

Reports show that the gelatinase activity of Seprase was completely blocked by serine-protease inhibitors, including DFP and PMSF [11, 25][22, 38]. Seprase could be affinity labelled by $\left[{ }^{3} \mathrm{H}\right]-\mathrm{DFP}$, but the proteolytically inactive $97 \mathrm{kDa}$ subunit could not [12][9]. This confirmed the existence of a serine protease active site on the dimeric form of the enzyme. This was further demonstrated by the loss of proteolytic activity upon the dissociation of its $97 \mathrm{kDa}$ subunits following treatment with acid, heat, or cysteine and histidine modifying agents [12][9]. Therefore, it may be 
concluded from this that Seprase activity is determined by the association of its subunits to form a proteolytically active dimer [27][24]. The proteolytic gelatinase activity of membrane bound Seprase was found to be maximal at neutral $\mathrm{pH}$ and was enhanced by a mixture of $2 \mathrm{mM}$ EDTA and $2 \mathrm{mM}$ DTT (which inhibits metaldependent proteases and activates cysteine proteases respectively) [11][38]. However, a previous study of the soluble form of Seprase demonstrated that EDTA had no effect on the proteolytic dipeptidyl peptidase activity and, contrary to previous reports DTT had a detrimental effect, with 5mM DTT causing a 10\% loss of activity [41][39].

A more recent study using a generated soluble recombinant Seprase (r-Seprase, 160$\mathrm{kDa}$ ), lacking cytoplasmic and transmembrane domains, found that in the presence of putative EDTA sensitive activators, r-Seprase was converted into $70-\mathrm{kDa}$ to $50 \mathrm{kDa}$ shortened forms of Seprase (s-Seprase) [42][40]. These shortened forms of Seprase exhibited a 7-fold increase in gelatinase activity, whereas levels of DPP activity remained unchanged [42][40]. Data shows that proteolytic truncation of the $\mathrm{NH}_{2-}$ terminal peptides of Seprase reduces steric hindrance for the gelatin substrate but not the dipeptidyl peptidase substrate, thereby increasing the gelatinolytic activity of Seprase [42][40]. Table 1 summarises some of the biochemical properties of Seprase. 


\section{Purification and Activity Detection of Seprase}

Seprase has been purified from cell membranes and shed vesicles of LOX human amelanotic melanoma cells $[3,11][3,38]$. It has also been purified from 9-day old chicken embryos [43][41]. Size exclusion chromatography (S-200) and affinity chromatography using wheat germ agglutinin (WGA)-agarose are two of the most widely used resins for Seprase purification [11, 12][9, 38]. Immunoaffinity purification of Seprase has also been utilised, with the mAb F19 pre-coated onto Sepharose CL-4B beads [10][42]. Soluble forms and isoforms of these membrane proteases are beginning to be found in biological fluids $[15,25][12,22]$. Recently our group have published the purification scheme for the soluble form of Seprase from bovine serum [25][22]. This purification procedure involved a combination of hydrophobic interaction chromatography, hydroxylapatite, and cibacron blue chromatography followed by size exclusion chromatography.

Until recently, the most sensitive assay available for Seprase detection involved gelatin zymography, which exploits the established gelatinase activity associated with Seprase [12][9]. However, this is not a quantitative assay. A semi-quantitative assay was developed based on the degradation of radiolabelled gelatin substrate and subsequent qualitative measurement of the released fragments [43][41]. Seprase was reported to possess prolyl dipeptidyl peptidase activity [15, 32, 40, 44][12, 29, 37, 43] and Ala-Pro-AFC was seen as a potential sensitive fluorogenic substrate. Interestingly, conflicting results exist with reports that Seprase has no such prolyl dipeptidyl peptidase cleavage activity $[12,45][9,44]$. 


\section{Tissue Distribution of Seprase}

Studies have shown that Seprase is transiently expressed in certain normal fetal mesenchymal tissues, during wound healing and in reactive stroma responding to epithelial cancers and some sarcomas $[7,8]$. Normal adult tissues as well as malignant epithelial, neural and haematopoietic cells are generally Seprase-negative. The initial identification of Seprase involved the study of six surface glycoproteins that were differentially expressed during normal development, proliferative activation and malignant transformation of mesenchymal cells and tissues [46][45]. The monoclonal antibody F19 was used to define the human cell-surface glycoprotein Seprase. The F19 antigen (now known as Seprase) was found to be expressed on cultured fibroblasts derived from various organs, several foetal mesenchymal tissues, scar tissue and a proportion of sarcoma cell lines. In normal adult tissues expression of the F19 antigen was restricted to occasional fibroblasts and to a set of pancreatic islet cells. The pattern observed in this initial study suggests that Seprase is a cell-surface marker for proliferating mesenchymal cells and that its expression may be induced by normal growth factors or during malignant transformation [46][45].

Another early study describes the induction of F19 in the reactive mesenchyme of epithelial tumours (carcinomas) [7]. Fibroblasts positive for the F19 antigen (Seprase) using immunohistochemical studies were found in primary and metastatic carcinomas including colorectal, breast, ovarian, bladder, and lung carcinomas. This study also analysed dermal incision wounds and found that F19 was strongly induced during scar formation. These studies suggest that the $\mathrm{F} 9^{+}$phenotype correlates with specialised fibroblast functions in wound healing, inflammation and malignant tumour growth [7]. Another important observation from this study is that the cellular immunostaining 
patterns obtained with the tumour tissue suggests that Seprase is localised exclusively in the cell membrane/cytoplasm of fibroblastic cells. This cellular staining is consistent with the cell surface localisation of Seprase in cultured fibroblasts [7].

Since these early reports, more studies have shown that Seprase is expressed in reactive human stromal fibroblasts [23][20]. Studies have confirmed the expression of Seprase in primary breast infiltrating ductal carcinoma, colon adenocarcinoma and lung adenocarcinoma and also in metastatic colon adenocarcinoma in the hepatic system [23, 47]. Several groups have shown Seprase to be expressed in the reactive stromal fibroblasts of human breast cancer and its absence in normal breast tissue [7, $10,16,48]$. As mentioned above, Seprase is expressed by infiltrating ductal carcinoma (IDC) cells in breast cancer patients; however it is not expressed by normal breast epithelia [23, 47, 49]. Further work has shown that Seprase expression is not confined to stromal fibroblasts but that the protease is also expressed in some types of malignant cells of epithelial origin [4, 15, 50-52]. Stromal expression of Seprase in IDC of the breast was associated with longer survival of patients [48]. Contrary to this, a recent study of patients with epithelial ovarian carcinoma has shown that the overall survival decreased with expression of Seprase protein $(p=0.03)$ [52]. This report suggests that the conflicting data may result from the previous studies having either small samples and series or short follow-up period [52]. Reports differ in the cellular localisation of FAP $\alpha$ and Seprase depicted by immunochemistry $[15,49]$. The apparent difference is thought to be partially due to the use of antibodies that recognise, with varying affinity, different epitopes exhibited by FAP $\alpha$ (derived from activated fibroblasts) and Seprase (derived from invasive cancer cells). 
Expression patterns of Seprase were examined in cervical carcinoma and cervical intraepithelial neoplasm [50]. This embraces both carcinoma in situ and the precursor lesions known as dysplasia or 'disordered differentiation'. Some micro-invasive carcinomas and all invasive carcinomas showed Seprase immunoreactivity in the cancer cells [50]. The findings in this study show a direct correlation between gelatinase expression and the malignant phenotype. Thus Seprase may be an early marker of tumour progression characterising Seprase expression with invasive growth. A separate study to support the concept was performed by Iwasa [4], whom examined Seprase expression in colorectal cancer specimens. Immunoblotting showed higher levels of Seprase protein in the cancer tissue than in normal colorectal tissue ( $p$ $<0.001)$. The results also revealed a significant correlation between Seprase expression and lymph node metastasis $(\mathrm{p}=0.033)$.

Expression patterns of Seprase in human gastric cancer were investigated using immunohistochemistry and the study showed that there were distinct differences in its expression between intestinal- and diffuse-type gastric cancer [51]. Results also showed, as in Iwasa [4], a correlation between Seprase expression and depth of invasion. In intestinal cancer, the stromal expression of Seprase significantly correlated with liver metastasis $(\mathrm{p}=0.0002)$ and lymph node metastasis $(\mathrm{p}<0.0001)$. In contrast, in diffuse-type cancer there was no correlation between stromal Seprase expression and lymph node metastasis $(\mathrm{p}=0.0821)$ [51]. A separate study looked at the expression of Seprase at the mRNA and protein level. This study found that Seprase expressing carcinoma tissues were more prominently found in the scirrhous type than in other types of gastric carcinoma [53]. 
Immunohistochemical studies have shown Seprase expression was induced in patients with idiopathic pulmonary fibrosis (IPF) [54]. Its expression pattern is restricted to fibroblasts in areas of ongoing tissue injury (Fig. 3. ref [54]). Seprase was recently identified for the first time on chondrocyte membranes under conditions that promoted cartilage resorption and elevated expression in cartilage from osteoarthritis (OA) patients [55]. The results from this study supported a role for Seprase in the mechanisms leading to cartilage degeneration in OA. Gene expression profiling in the murine model showed a 7-fold increase in Seprase expression in inflamed, compared to non-inflamed paws [56].

A study by Huber [57] found that Seprase was expressed in benign and malignant melanocytic skin tumours. This is in contrast to the findings in benign epithelial tumours, in which little or no expression of Seprase was observed on stromal fibroblasts [7, 47]. Normal adult skin, however, did not have any detectable Seprase activity. These contradictory results could be explained if melanocytic naevi (moles) are considered as precursor lesions for melanoma development, characterised by constitutively-active tumour stroma $[57,58]$. Gene expression studies have identified Seprase to be uniquely overexpressed in aggressive fibromatosis [59]. Aggressive fibromatosis is locally invasive but rarely metastasises. There are histologic similarities between this disease and the proliferative phase of wound healing.

To further support the concept that Seprase is expressed during wound healing, studies have shown that stellate cells at the tissue remodelling interface of cirrhosis in humans, express Seprase [60, 61]. Hepatic stellate cells (HSCs) are a known major source of ECM degrading enzymes and protease inhibitors of hepatic tissue 
remodelling [62]. It is thought that Seprase may contribute to the (HSC)-induced ECM changes of cirrhosis. Seprase expression was also detected in the hepatic parenchyma of patients with chronic hepatitis $\mathrm{C}$ virus (HCV) infection. In fact, Seprase expression correlates with the degree of fibrosis in HCV $(p<0.0001)$ [63]. This adds considerable weight to the assertion that Seprase has a role in the pathogenesis of chronic liver disease.

Another study involving the Xenopus laevis Seprase homologue describes the enzymes increased expression during hormone-induced tail resorption, indicating a possible role in tissue remodelling [33]. An extension of this concept is that Seprase has been found to be expressed during mouse embryo development [64]. However, Seprase-deficient mice showed no overt developmental defects and were viable. In order to analyse Seprase expression at various stages of embryonic development, mice deficient in Seprase but expressing $\beta$-galactosidase under the control of the Seprase promoter were developed (Seprase ${ }^{-/-}$lacZ). These Seprase ${ }^{-/-}$lacZ mice expressed $\beta$ galactosidase at regions of active tissue remodelling during embryogenesis supporting a role for Seprase in tissue remodelling processes [64].

Overall, Seprase has been seen to be expressed in stromal fibroblasts of more than $90 \%$ of all epithelial tumours including lung, colorectal and breast carcinomas (primary and metastatic) [7]. It has also been shown to be expressed in post-natal nontumour tissues [15], in a proportion of bone and soft tissue sarcoma tumour cells [47], in granulation tissue of healing wounds [7], and on pancreatic cells [46]. However, normal adult tissue, benign and premalignant epithelial lesions are generally Seprase negative. Seprase-positive cells were found in close proximity to the endothelial cells 
of the tumour capillaries and surround the tumour nodules [7, 46, 65]. These suggest that Seprase may have a critical role to play in altering the microenvironment to promote tumour growth, thus enhancing the theory that metastatic effects may depend on proteolytic enzymes derived not only from tumour cells but also from stromal cells. 


\section{Physiological and Pathological Roles for Seprase}

High levels of Seprase activity have been positively correlated with the invasive behaviour of many malignantly transformed cells but its function in malignancy is still unknown $[3,11,66]$. There is evidence that Seprase could act as both a tumour suppressor and tumour promoter. Sections 6.1 and 6.2 put the case forward for both situations.

\subsection{Tumour Suppression}

There is growing evidence that Seprase may play a role as a tumour suppressor [6769]. Initial studies have shown the loss of DPPIV expression as normal melanocytes progress to malignant melanoma [69]. Experiments have shown that the re-expression of DPPIV was able to change the mouse melanoma cells to a more differentiated and normal phenotype with a return to dependence on exogenous growth factors [69]. Wesley [69] observed that the re-establishment of dependence on exogenous growth factors occurred even when a catalytically inactive mutant of DPPIV was expressed. This group accredited this to the expression of endogenous Seprase which was coinduced when the mutant DPPIV was expressed. More recent studies have provided direct evidence in the case for Seprase as a tumour suppressor. It was observed that the expression of Seprase decreased the tumourigenicity of mouse melanoma cells in animals and restored contact inhibition and growth factor dependence [67]. Another interesting result from this study is that the catalytic mutant of Seprase contributed to the tumour suppression in the absence of active protease activity. In addition to this, the study demonstrated that while DPPIV expression induced Seprase expression, the converse was not so; i.e. Seprase expression did not induce DPPIV expression. 
Therefore, it was concluded that the tumour-suppressive activities of wild-type and mutant Seprase are most likely due to the inherent abilities of Seprase.

\subsection{Tumour Progression}

The role of Seprase in breast cancer has been investigated using human breast cancer cell lines that normally express Seprase (MDA-MB-435 and MDA-MB-436) [70]. Anti-sense suppression of Seprase rendered these cells sensitive to serum starvation while control transfectants with high levels of Seprase expression grew well in the absence of serum [70]. Goodman [70] concluded that the breast cancer cells with high levels of Seprase expression are less dependent on exogenous serum factors for growth and have gained independence from normal growth regulatory controls. Independence from normal growth regulation is a key characteristic of malignancy transformed cells that distinguishes them from normal cells [71].

Seprase expression was also engineered in the human breast cancer cell line MDAMB-231, which lacks normal Seprase expression [72]. A mouse model was utilised to demonstrate that Seprase-expressing tumours grew more rapidly and were highly vascular when compared to tumours of control transfectants which lacked Seprase expression [72]. This group did find that when these cells were grown in vitro, cells that did express Seprase grew at the same rate as those that did not. This indicated that Seprase had a more noticeable effect on tumour cell growth in the mouse mammary fat pad environment. For tumours to grow and integrate into the surrounding normal tissue, they must attract a blood supply (angiogenesis), which sustains growth. This study was the first evidence for a pro-angiogenic function for Seprase and it can be concluded that Seprase expression promotes growth of breast cancer tumours at least 
in part by driving angiogenesis [72]. This conclusion is supported by studies showing that Seprase mRNA is up-regulated by endothelial cells undergoing re-organisation and capillary morphogenesis [73]. Both these findings together suggest that Seprase expression by breast cancer cells favourably alters the tumour microenvironment.

Further evidence of these growth-promoting effects of Seprase have been described $[29,74]$. Murine Seprase was transfected into HEK293 human embryonic kidney cells. It was then shown that the tumours derived from these Seprase expressing cells grew more rapidly than the control transfectants. This group also demonstrated in an animal model, that antibodies found to inhibit the dipeptidase activity of Seprase, also suppressed the growth of tumours which were derived from cells expressing Seprase [29]. Wang and co-workers [75] found that the over-expression of Seprase in the human hepatic stellate cell (HSC) cell line LX-2 increased cell adhesion, migration and invasion. Interestingly, this group found that Seprase proteolytic activity was not necessary for these functions. These findings further support a pro-fibrogenic role for Seprase by indicating that, in addition to its enzymatic functions, Seprase has important non-enzymatic functions [75]. Overall, it can be concluded from these studies that Seprase activity mediates in some way the increased tumour growth. Recently increased DPPIV expression and enzymatic activity has been shown to be associated with tumour grade severity in human astrocytic tumours [76]. There is no evidence to date that Seprase dipeptidyl peptidase activity can be correlated with tumour grade.

In summary there is an obvious discrepancy between Seprase function in tumour promotion and tumour suppression. It is proposed by some researchers that Seprase 
expression has a profound effect on cells that do not normally express Seprase and that the context in which Seprase is expressed determines the biological response to Seprase (either promotion or inhibition of growth) [77]. This group has created a model that explains all the reported findings so far. It describes how Seprase associates with membrane-bound signalling molecules causing transmission of growth stimulatory or inhibitory signals (Fig. 2. ref [77] for an example of stimulatory signals). The factor that determines this must reside in the signalling molecules that are available for interaction with Seprase on the cells. Therefore it was concluded that Seprase carries out its biological functions in a cell-context dependent manner through a combination of its protease activity and its ability to form complexes with other cell surface molecules [77].

\subsection{Seprase complexes in cellular invasiveness}

Seprase associates with $\alpha_{3} \beta_{1}$ integrin, DPPIV, MMP-2, membrane-type 1 MMP and uPA at the invadopodia of human malignant cells and so may interact with these proteinases and receptors and with associated cascades $[3,55,78,79]$.

The integrin family of transmembrane adhesion proteins have been shown to exhibit multiple functions, including adhesion to ECM and their localisation at invadopodia [79]. One theory is that integrins are involved in recruiting proteases to these sites of cell invasion. The $\alpha_{3} \beta_{1}$ integrin has been shown to associate with Seprase and it is thought that $\alpha_{3} \beta_{1}$ may participate in the formation of functional invadopodia by docking Seprase (Fig. 5. Panel A and D ref [79]). 
Seprase and DPPIV can form a complex localised at the invadopodia of fibroblasts on collagenous fibres that has both gelatinolytic and gelatin binding activities. This has been shown to facilitate cell migration [14, 18, 80, 81]. Seprase and DPPIV are highly homologous with both enzymes having the same domain structure (Fig. 1. ref [14]). Seprase shows 50\% amino acid identity with DPPIV over the entire sequence, with almost $70 \%$ identity in the catalytic domain $[12,16,21]$. The Ser-Asp-His catalytic triad is conserved in both enzymes and their genes map to the same region of the human chromosome 2. Despite their shared structural features, Seprase and DPPIV differ in their tissue distribution and expression [65]. Seprase can form heteromeric complexes with DPPIV and the formation of the DPPIV-Seprase complex, which exhibits both prolyl peptidase activity and gelatinase activity, is necessary for cell migration on a collagen substrate [45]. It is possible that the two enzymes cooperate for efficient degradation of substrates and their consequent biological functions. The exact natures of the homodimer and heterodimer complexes of Seprase are poorly understood.

A recent study has shown that Seprase-Urokinase-type plasminogen activator receptor (UPAR) membrane complexes are associated with the invadopodia of LOX cells, suggesting their co-operative roles in tumour invasion (Fig. 1. ref [78]). Urokinase plasminogen activator (uPA), a serine protease, converts the tissue zymogen plasminogen into plasmin. Plasmin has the ability to degrade most proteins in the ECM, including type IV collagen, laminin and fibronectin. In model systems, both the inhibition of uPA activity and the prevention of uPA binding to its receptor have been shown to limit the formation of metastasis [4]. Thus, Seprase may also be a potential candidate for anti-metastatic therapies. The interaction of uPA and the integrins have 
been shown to regulate both adhesive and signalling activities of integrins [79]. The formation of the Seprase-uPAR membrane complexes is dependent upon both the cytoskeleton and integrins, specifically the $\beta_{1}$ integrin [78]. 


\subsection{Antiplasmin Cleaving Enzyme (APCE)}

As mentioned in Section 3, Lee and co-workers [82] have recently identified the soluble form of Antiplasmin Cleaving Enzyme (APCE) as Seprase. $\alpha_{2}$-Antiplasmin (AP) is a plasma glycoprotein of the Serpin (serine protease inhibitor) superfamily and is the primary physiological inhibitor of plasmin, a key enzyme in fibrin degradation [83]. The fibrinolytic system leads to the generation of plasmin from plasminogen through the action of Tissue or Urokinase Plasminogen Activator (t-PA or uPA). Studies into $\alpha_{2}$-antiplasmin have shown that it is present in the blood in a larger 'pro'-form, $\alpha_{2} \mathrm{AP}$ PRO and in a smaller mature form of $\alpha_{2} \mathrm{AP}_{\mathrm{ACT}} . \alpha_{2} \mathrm{AP}_{\mathrm{PRO}}$ has 464 amino acid residues, with Methionine at the N-terminus. The mature form $\alpha_{2} \mathrm{AP}_{\mathrm{ACT}}$, has 452 amino acid residues, with Asparagine at its $\mathrm{N}$-terminal $[84,85]$. Both forms have been shown to be present in the blood $\left(66 \% \alpha_{2} \mathrm{AP}_{\mathrm{ACT}} ; 34 \%\right.$ $\left.\alpha_{2} \mathrm{AP}_{\mathrm{PRO}}\right)$ and they both form a stable complex with plasmin. However the 'pro'-form has remarkably less capacity of cross-linking fibrin (Fig. 5.) [86]. When $\alpha_{2} \mathrm{AP}_{\mathrm{ACT}}$ is cross-linked to fibrin (during clot formation), it retains the ability to effectively inhibit plasmin and protect fibrin from proteolysis. The processing of $\alpha_{2} \mathrm{AP}_{\mathrm{PRO}}$ to $\alpha_{2} \mathrm{AP}_{\mathrm{ACT}}$ was shown to involve a plasma protease that cleaved the Pro ${ }^{12}-\mathrm{Asn}^{13}$ bond of the $\alpha_{2} \mathrm{AP}_{\mathrm{PRO}}$ protein [82]. This protease is called Antiplasmin Cleaving Enzyme (APCE).

APCE has been purified from human plasma using an initial ammonium sulphate fractionation, followed by hydrophobic, anion exchange, T-gel thiophilic, and immunoaffinity chromatographies [85]. The fact that APCE is found in human plasma and cleaves $\alpha_{2} \mathrm{AP}$ PRO suggests that one of its physiologic functions is the regulation of $\alpha_{2} \mathrm{AP}_{\mathrm{ACT}}$ availability for plasmin inhibition within cross-linked fibrin [85]. Plasmin is resistant to $\alpha_{2}$-antiplasmin inhibition when it is associated with the plasma membrane 
[87]. A study analysing the regulation of liver regeneration by the plasmin $/ \alpha_{2}$-AP system suggests that this system plays an important role in the hepatic repair via proteolysis of the matrix elements and the clearance of cellular debris from the injured site [88]. Altered fibrin turnover may be responsible for tumour-promoting effects in several ways [89]. In clinical situations where fibrin formation is likely, the development of an agent that inhibits APCE might result in decreased amount of $\alpha_{2} \mathrm{AP}_{\mathrm{ACT}}$ available for cross-linking to fibrin as thrombi develop or as inflammation progresses. Abnormalities of haemostasis during tumour growth and metastasis have been observed and it has been shown that the ECM of neoplastic tissue is abnormally rich in fibrin bundles and is mixed with other stromal components [87]. Degradation of fibrin, fibrinogen and the ECM proteins by plasmin, in addition to the concomitant activation of the Urokinase Receptor by Urokinase Plasminogen Activator, has been suggested to facilitate tumour cells invasion and metastasis [89]. It has also been shown that elevated plasma levels of cross-linked fibrinogen indicated cancer-related fibrin deposition and fibrinolysis [89]. 


\section{Substrate Specificity}

Most peptidases, even those that lack specificity, are unable to hydrolyse peptide bonds formed by proline due to the unique structure of the imino-acid and the special constraints it exerts on the peptide backbone structure [90]. Proline residues appear near the amino terminus of many biologically active peptides and appears to protect the peptide against degradation [90]. Seprase is one of a small number of peptidases which are capable of hydrolysing the proline peptide bonds.

The identification of key substrates recognised by Seprase may provide a better understanding of the physiological role and of the pathways that control the activation of stromal fibroblasts during tumourigenesis. Seprase has been shown to have two proteolytic activities. Firstly it is a gelatinase $[3,11,12]$ and secondly an N-terminal post-prolyl amino peptidase that can cleave Ala-Pro-AFC [26, 36, 51, 91]. Both the gelatinase and dipeptidyl peptidase activities of Seprase are mediated by an active site serine $^{624}[12,23]$. Table 2 illustrates the kinetic constants obtained in studies of dipeptide substrates. Most serine proteases have no absolute substrate specificity [30]. They can cleave peptide bonds with a variety of side chains adjacent to the scissile bond. The $\mathrm{S}_{1}-\mathrm{P}_{1}$ hydrogen bond is a very important factor in the proper substrate orientation and the transition state stabilisation. Proline residues do not possess main chain NH groups and therefore the architecture of the $\mathrm{S}_{1}$ binding site is evolved to be much more specific in Seprase [30].

Substrate specificity studies using zymography have shown that Seprase degrades gelatin and thermally denatured type I and type IV collagens but not laminin, fibronectin, fibrin or casein $[3,12]$. The gelatinase activity distinguishes Seprase from 
DPPIV, which does not have gelatinase activity [22, 23]. However, an earlier report by Bermpohl and co-workers [24] suggested that DPPIV does have gelatinase activity.

However, given that neither gelatin nor denatured collagen is a component of the ECM, the actual effect of Seprase on its alleged ECM substrate, collagen, is important to clarify. A recent study by Christiansen [92] has attempted to do this by examining the potential proteolytic effects of both Seprase and APCE toward purified types I, III and IV Collagens as substrates. In addition to this the individual effect of Seprase/APCE in combination with selected metalloproteinases (MMPs) that also participate in ECM remodelling was explored. This study demonstrated that neither Seprase nor APCE cleaved Collagen I into smaller peptides. This was also seen using Collagen III as substrate. The study also indicated that Seprase/APCE did not act secondarily to MMP-9 in the digestion of type IV Collagen. This group concluded that Seprase works in synchrony with other proteinases to cleave partially degraded or denatured Collagen I and III as ECM is excavated, and that derivative peptides might function to regulate malignant cell growth and motility [92].

\subsection{Modifications of bioactive peptides}

The endopeptidase activity of Seprase may function to regulate bioactive peptides. Due to the presence of a soluble form of Seprase in serum, any peptide circulating in the blood carrying a proline residue in the penultimate $\mathrm{N}$-terminal position is a potential candidate substrate for its biological enzymatic activity. A proline positioned near the end of a peptide produces a significant 'kink'. The natural substrates of Seprase are unknown, although the serum form has been shown to cleave the Pro ${ }^{12}$ - 
$\mathrm{Asn}^{13}$ bond of $\alpha_{2}$ antiplasmin $\left(\alpha_{2} \mathrm{AP}\right.$ PRO $)$ producing the Asn- $\alpha_{2}$ antiplasmin $\left(\alpha_{2} \mathrm{AP}\right.$ ACT $)$

[85]. The cleaved protein binds fibrin more efficiently and slows clot lysis by plasmin more effectively than full-length $\alpha_{2}$ antiplasmin $\left(\alpha_{2} \mathrm{AP} \mathrm{PRO}_{\mathrm{PR}}\right)$. Based on the Seprase cleavage site in $\alpha_{2} A P_{P R O}$, the specificity of Seprase in the $\mathrm{P}_{4}-\mathrm{P}_{4}$ ' positions were defined [93]. The study confirmed that Seprase requires a Proline in the $\mathrm{P}_{1}$ position and Glycine (or D-amino acids) at the $\mathrm{P}_{2}$ position (Fig. 6.) $[25,93]$. Seprase has been shown to have a broader tolerance at the $\mathrm{P}_{4}, \mathrm{P}_{3}, \mathrm{P}_{1}$, and $\mathrm{P}_{2}$ ' positions. In the $\mathrm{P}_{3}$ position, Seprase had a preference for Ala and Ser. Less activity was observed against charged and aromatic amino acid residues, suggesting a preference for small, uncharged amino acids at the $\mathrm{P}_{3}$ position. Seprase seems to have a broader specificity at the $\mathrm{P}_{4}$ position. Compared to the previous study mentioned above, it was found that Seprase has a preference for Phe or Met at the $\mathrm{P}_{1}$ position and least tolerance of His or Glu $[25,93]$.

Seprase has been shown to have a preference for N-blocked peptide substrates. Studies have shown that Seprase cleaves formyl-, benzyloxycarbonyl- and biotinylblocked substrates, which DPPIV cleaved poorly [94]. The substrate preferences as defined by Edosada [94] were used to design a peptidyl-chloromethyl ketone (cmk) that inhibited Seprase but not DPPIV.

A fluorescence resonance energy transfer (FRET) peptide (Table 2.) was developed that contained the APCE-sensitive Pro ${ }^{12}-\mathrm{Asn}^{13}$ bond within the $\mathrm{Thr}^{9}-\mathrm{Gln}^{16}$ sequence of Met- $\alpha_{2} \mathrm{AP}\left(\alpha_{2} \mathrm{AP}\right.$ PRO) [85]. Kinetic data using the FRET peptide has shown Seprase to have high affinity and kinetic efficiency, indicating that residues in the $\mathrm{P}_{4}-\mathrm{P}_{4}$ ' region contribute to the substrate specificity [82]. The $\mathrm{k}_{\mathrm{cat}} / \mathrm{K}_{\mathrm{m}}$ value for cleavage of 
the FRET peptide is $\sim 8$-fold higher than for Z-Gly-Pro-AMC and $\sim 12$-fold higher than for Ala-Pro-AFC (Table 2.) [85].

Combined results from the Edosada [93] study also provided a composite $\alpha_{2}$ APderived peptide substrate for Seprase namely, Ala-Ser-Gly-Pro-Ser-Ser. Comparing the kinetic parameters for the parental (TSGP-NQ) and composite $\alpha_{2} \mathrm{AP}$-derived peptide substrate (ASGP-SS) shows that the $\mathrm{K}_{\mathrm{m}}$ value for the cleavage of the composite substrate was 3.3 fold higher than the parental substrate $\left(\mathrm{K}_{\mathrm{m}}=4.3 \mu \mathrm{M}\right.$ and $1.3 \mu \mathrm{M}$ respectively). However, a concomitant 3.4 fold increase in $\mathrm{k}_{\text {cat }}$ was observed, yielding a nearly equivalent catalytic efficiency $\left(\mathrm{k}_{\text {cat }} / \mathrm{K}_{\mathrm{m}}\right)$ for each peptide $\left(\mathrm{k}_{\mathrm{cat}} / \mathrm{K}_{\mathrm{m}}=\right.$ $1.3 \times 10^{6} \mathrm{M}^{-1} \mathrm{~s}^{-1}$ and $1.2 \times 10^{6} \mathrm{M}^{-1} \mathrm{~s}^{-1}$ respectively).

Ultimately, the identification of the natural substrates of Seprase and the functions of Seprase activated peptides remains an important area to be investigated. 


\section{Possible clinical significance of Seprase}

Invasion with or without metastatic spread of cancer to distant sites has already occurred in a significant number of patients by the time their disease is detected [95]. Significant improvement in a patient's survival may be achieved by halting the invasion process and containing the metastatic spread and growth of the disease. This may be achieved in several possible ways;

\subsection{Direct inhibition of Seprase protease activity}

An appealing target is the inhibition of tumour growth promotion by Seprase protease activity. Seprase is inhibited by the serine protease inhibitors DFP $(0.005 \mathrm{mM})$, PMSF (1mM), AEBSF $(5 \mathrm{mM})$ and APSF $(0.5 \mathrm{mM})[11,12,16,25]$. The $170 \mathrm{kDa}$ protease was sensitive to other inhibitors, such as $\mathrm{NEM}$ and $\mathrm{HgCl}_{2}$, that bind the sulfhydryl group of amino acid residues of the proteases [11]. These inhibition studies suggest that Seprase contains a catalytically active serine residue.

A series of dipeptide proline diphenyl phosphonates were designed against DPPIV and Seprase [96]. The most potent inhibitor for both enzymes was found to be Gly$\operatorname{Pro}^{\mathrm{P}}(\mathrm{OPh})_{2}$, which exhibited overall second-order rate constants of inactivation of $5.24 \times 10^{5} \mathrm{M}^{-1} \mathrm{~min}^{-1}$ and $1.06 \times 10^{4} \mathrm{M}^{-1} \mathrm{~min}^{-1}$ against DPPIV and Seprase respectively. In the case of Seprase, it was found that the nature of the $\mathrm{P}_{2}$ residue of the inhibitor had a less pronounced effect on the second order rate constants, in contrast to DPPIV. It was found for DPPIV that the second order rate constants varied by one order of magnitude between the most effective $\left[\mathrm{Gly}-\mathrm{Pro}^{\mathrm{P}}(\mathrm{Oh})_{2}\right]$ and the least effective [Ala$\operatorname{Pro}^{\mathrm{P}}(\mathrm{Oh})_{2}$ ] inhibitors. This group also found that $\operatorname{Gly}_{-\operatorname{Pro}^{\mathrm{P}}}(\mathrm{Oh})_{2}$ and $\operatorname{Tyr} \mathrm{Pro}^{\mathrm{P}}(\mathrm{Oh})_{2}$ 
exerted a considerable dose dependent anti-invasive effect on the LOX melanoma cell line, in vitro [96].

A recent study by Tran [97] explored the structure-activity relationship of various Nacyl-Gly-, N-acyl-Sar- and N-blocked-boroProline derivatives against three prolyl peptidases, Seprase, DPPIV and POP. Several N-acyl-Gly- and N-blocked-boro compounds showed low nanomolar inhibitory activity against Seprase and POP and selectively against DPPIV. N-Acyl-Sar-boroPro analogs retained selectivity against DPPIV and potent POP inhibitory activity but displayed decreased Seprase inhibitory activity. These results provide a foundation for future studies aimed at developing selective inhibitors for Seprase and POP [97].

The inhibition of the catalytic activity of Seprase with anti-catalytic antibodies has been investigated. It was found that the tumour-promoting effects of Seprase expression were inhibited by the use of these antibodies [29, 45]. Cheng and coworkers also observed the over-expression of Seprase, leading to increased tumourigenicity, compared to a mutated S624A Seprase [91]. In this same study, Seprase activity was shown to be inhibited by Val-boroPro (PT-100, called Talabostat), a boronic acid inhibitor, with an $\mathrm{IC}_{50}$ of $4 \times 10^{-8} \mathrm{~mol} / \mathrm{L}$ [91]. However, this inhibitor was also found to inhibit DPP IV , DPP-7, -8 and -9 [94, 98]. A further study has demonstrated that PT-100 could be used as an anti-cancer agent with a unique mechanism of action [99]. PT-100 has the potential to complement chemotherapy. Combination treatment using Taxol or Cisplatin resulted in significantly greater tumour inhibition and also rejection in $10 \%$ and $50 \%$ of mice respectively [100]. 
N-acyl-Gly-Pro dipeptides were identified as Seprase selective substrate motifs and a second boronic acid inhibitor was designed, Ac-Gly-BoroPro [94]. It inhibited these prolyl peptidases with $K_{i}$ values ranging from $\sim 9$ - to 5400-fold higher than that for Seprase inhibition $\left(\mathrm{K}_{\mathrm{i}}=23 \mathrm{nM}\right.$ for Seprase) [94]. This indicated that the Ac-Gly-Pro motif conferred significant Seprase selectivity and suggests that this could possibly be used to test Seprase as a therapeutic target.

These studies together suggest that Seprase activity plays an important role in the promotion of tumour growth and that the Seprase protease is a good potential target for therapies designed to slow tumour growth.

\subsection{Seprase - a specific target for anti-tumour agents}

Surface expressed Seprase represents an additional potential target for immunolocalisation and immunotherapy of epithelial cancers. Since a large proportion of carcinomas contain an abundance of Seprase positive stroma, it is possible that they would be accessible to circulating mAb. Several groups have developed antibodies directed against Seprase. Antibodies were developed using the Seprase specific mAbF19 as a model and humanising the antibody [101-105].

A phase I study investigated the effects of the mAbF19 targeted against metastatic colon cancer [65]. This study concluded that there were no toxic effects associated with intravenous administration of iodine ${ }^{131}$ labelled mAbF19 ( $\left.{ }^{131} \mathrm{I}-\mathrm{mAbF} 19\right)$. Increased expression of Seprase in primary and metastatic colorectal carcinomas with limited expression in normal adult tissue was also observed during this study. This highly selective expression pattern allowed for imaging of carcinoma lesions as small 
as $1 \mathrm{~cm}$ in diameter. A logical concern with regards to the development of stromal targeting for cancer therapy is the notion that the stromal response to cancer (at the cellular and molecular level [65]) is similar to that of wound healing and Seprase is known to be expressed in healing dermal incisions [46]. However, the patients involved in this study would have had extensive scarring due to surgery but did not show any localisation of ${ }^{131} \mathrm{I}-\mathrm{mAbF} 19$ at these sites. Another phase I trial and limited phase II trial have been conducted with an unconjugated, humanized version of monoclonal antibody F19 to Seprase called sibrotuzumab [105, 106]. Results from this trial found that sibrotuzumab was well tolerated and relatively safe and a pharmacokinetic model has been developed for it [107]. Similar to the results obtained in the previous phase I trial [65], trace labelling with ${ }^{131} \mathrm{I}$ and detection imaging revealed that sibrotuzumab specifically accumulated in the tumours and not in the normal tissues [101]. These studies suggest that mAbF19 has potential diagnostic and therapeutic applications and could be constructed to provide novel immune and nonimmune effector functions $[65,77]$.

\subsection{Disruption of Seprase signalling}

The targeting of antigens selectively expressed on the surface of tumour stromal fibroblasts or tumour capillary endothelial cells is currently being explored for the immunotherapeutic treatment of cancer [103, 108, 109]. By targeting or preventing the generation of tumour stroma or angiogenic blood vessels, tumour lesions may be deprived of the essential support services or nutrients required for survival and growth [110]. For reasons discussed in Section 8.2, Seprase is an important antigen for targeted therapy of the tumour stroma. [5] 
Garin-Chesa and co-workers [7] propose that radiolabelled or toxin-conjugated mAbs or inflammatory $\mathrm{mAb}$ isotypes detecting Seprase may be used to induce cell damage in the Seprase positive supporting tumour stroma. This would lead to tumour cell necrosis (death) and inflammatory cell infiltrates. Recruitment of additional Seprase positive reactive fibroblasts would renew the target cell population and aid formation of fibrous capsules enclosing and isolating epithelial tumour cells.

Studies in murine models have shown that immunologic targeting of the tumour vasculature, a key element of tumour stroma, can lead to protective immunity in the absence of significant pathology [109]. Targeting the tumour stroma, instead of tumour cells, reduces the incidence of immune evasion. Genetically more stable cells in the tumour stroma may prove to be a promising cellular target for cancer immunotherapy. Recent findings suggest that the tumour-stromal antigen Seprase can serve as a novel target for active vaccination against cancer, especially if combined with chemotherapy [111]. Tumour associated fibroblasts are also the primary source of Collagen type I, which has been shown to contribute to decreased chemotherapy drug uptake in tumours and play significant role in regulating tumour sensitivity to a variety chemotherapies [111]. In this study Loeffler and co-workers constructed an oral DNA vaccine which targets Seprase. This vaccine successfully suppressed primary tumour cell growth, metastasis of multi-drug resistant murine colon and breast carcinoma. Furthermore, tumour tissue of Seprase-vaccinated mice revealed markedly decreased Collagen type I expression and up to $70 \%$ greater uptake of chemotherapeutic drugs. Most importantly, Seprase vaccinated mice treated with chemotherapy showed a 3-fold prolongation in lifespan and marked suppression of tumour growth, with $50 \%$ of the animals completely rejecting a tumour cell challenge. 
An important note from this article is that the DNA vaccine did not impair wound healing or damage normal tissue [111]. These are important factors if considering a Seprase vaccine as a potential immunotherapy.

\section{Conclusion}

In conclusion, since the discovery of Seprase in 1986 [7, 9], a lot of research has been performed on the localisation and expression of this protease. However, more research is needed on the biochemical and functional properties of this peptidase. Despite the numerous reports with suggestions on possible functions of the enzyme, the physiological role of Seprase has not been elucidated. Seprase does seem to have an important role in malignant cell invasion and metastasis by degrading the ECM, albeit working in synchrony with MMPs. Seprase may be involved in the development of over $90 \%$ of epithelial cancers and it has a potential as a predictive marker for the disease. The availability of a potent and selective, in vitro and in vivo applicable Seprase-inhibitor opens new perspectives for further studies of the physiological function of Seprase. Seprase regulation might be operative at different levels; genetic, post translational, hormonal and kinetic, but the mechanisms involved and the relative importance of these putative regulation strategies are not known. Further studies in this area would provide vital information on Seprase regulation and possibly elucidate a physiological role for the protease. This would ultimately tell us a lot more about the potential for Seprase to be used as a target for selective anticancer therapies. 


\section{Acknowledgments}

The authors would like to thank the Irish Research Council for Science Engineering and Technology (IRCSET) and Sera Scientific Ltd. for the financial support for Dr. Pamela O'Brien.

\section{References}

[1] M.H. Sieweke and M.J. Bissell, The tumor-promoting effect of wounding: a possible role for TGF-beta-induced stromal alterations, Crit. Rev. Oncog. 5 (1994) 297-311.

[2] M.J. Bissell and D. Radisky, Putting tumours in context, Nat. Rev. Cancer 1 (2001) 46-54.

[3] W.L. Monsky, C.Y. Lin, A. Aoyama, T. Kelly, S.K. Akiyama, S.C. Mueller and W.T. Chen, A potential marker protease of invasiveness, seprase, is localized on invadopodia of human malignant melanoma cells, Cancer Res. 54 (1994) 5702-5710.

[4] S. Iwasa, K. Okada, W.T. Chen, X. Jin, T. Yamane, A. Ooi and M. Mitsumata, 'Increased expression of seprase, a membrane-type serine protease, is associated with lymph node metastasis in human colorectal cancer', Cancer Lett 227 (2005) 229-236.

[5] C.A. Abbott and M.D. Gorrell. in: Langner, J. and Ansorge, S., (Eds). Ectopeptidases: CD13/Aminopeptidase N and CD26/Dipeptidylpeptidase IV in Medicine and Biology, Kluwer Academic/Plenum Publishers, New York. 2002, pp. 171-195. 
[6] J.C. Barrett, N.D. Rawlings and J.F. Woessner, Handbook of Proteolytic Enzymes, Academic Press, London 1998.

[7] P. Garin-Chesa, L.J. Old and W.J. Rettig, Cell surface glycoprotein of reactive stromal fibroblasts as a potential antibody target in human epithelial cancers, Proc. Natl. Acad. Sci. U.S.A. 87 (1990) 7235-7239.

[8] W.J. Rettig, P. Garin-Chesa, J.H. Healey, S.L. Su, H.L. Ozer, M. Schwab, A.P. Albino and L.J. Old, Regulation and heteromeric structure of the fibroblast activation protein in normal and transformed cells of mesenchymal and neuroectodermal origin, Cancer Res. 53 (1993) 3327-3335.

[9] W.J. Rettig, P.G. Chesa, H.R. Beresford, H.J. Feickert, M.T. Jennings, J. Cohen, H.F. Oettgen and L.J. Old, Differential expression of cell surface antigens and glial fibrillary acidic protein in human astrocytoma subsets, Cancer Res 46 (1986) 6406-12.

[10] W.J. Rettig, S.L. Su, S.R. Fortunato, M.J. Scanlan, B.K. Raj, P. Garin-Chesa, J.H. Healey and L.J. Old, Fibroblast activation protein: purification, epitope mapping and induction by growth factors, Int. J. Cancer 58 (1994) 385-392.

[11] A. Aoyama and W.T. Chen, A $170-\mathrm{kDa}$ membrane-bound protease is associated with the expression of invasiveness by human malignant melanoma cells, Proc. Natl. Acad. Sci. U.S.A. 87 (1990) 8296-8300.

[12] M.L. Pineiro-Sanchez, L.A. Goldstein, J. Dodt, L. Howard, Y. Yeh, H. Tran, W.S. Argraves and W.T. Chen, Identification of the $170-\mathrm{kDa}$ melanoma membrane-bound gelatinase (seprase) as a serine integral membrane protease, J. Biol. Chem. 272 (1997) 7595-7601.

[13] S. Mathew, M.J. Scanlan, B.K. Mohan Raj, V.V. Murty, P. Garin-Chesa, L.J. Old, W.J. Rettig and R.S. Chaganti, The gene for fibroblast activation protein 
alpha (FAP), a putative cell surface-bound serine protease expressed in cancer stroma and wound healing, maps to chromosome band 2q23, Genomics 25 (1995) 335-337.

[14] W.T. Chen and T. Kelly, Seprase complexes in cellular invasiveness, Cancer Metastasis Rev. 22 (2003) 259-269.

[15] W.T. Chen, T. Kelly and G. Ghersi. Current Topics in Developmental Biology, Academic Press 2003, pp. 207.

[16] M.J. Scanlan, B.K. Raj, B. Calvo, P. Garin-Chesa, M.P. Sanz-Moncasi, J.H. Healey, L.J. Old and W.J. Rettig, Molecular cloning of fibroblast activation protein alpha, a member of the serine protease family selectively expressed in stromal fibroblasts of epithelial cancers, Proc. Natl. Acad. Sci. U.S.A. 91 (1994) 5657-5661.

[17] P. Busek, R. Malik and A. Sedo, Dipeptidyl peptidase IV activity and/or structure homologues (DASH) and their substrates in cancer, The International Journal of Biochemistry \& Cell Biology 36 (2004) 408-421.

[18] W.T. Chen, DPPIV and seprase in cancer invasion and angiogenesis, Adv. Exp. Med. Biol. 524 (2003) 197-203.

[19] J.S. Rosenblum and J.W. Kozarich, Prolyl peptidases: a serine protease subfamily with high potential for drug discovery, Current Opinion in Chemical Biology 7 (2003) 496-504.

[20] B. Bauvois, Transmembrane proteases in cell growth and invasion: new contributors to angiogenesis? Oncogene 23 (2004) 317-329.

[21] L.A. Goldstein, G. Ghersi, M.L. Pineiro-Sanchez, M. Salamone, Y. Yeh, D. Flessate and W.T. Chen, Molecular cloning of seprase: a serine integral 
membrane protease from human melanoma, Biochim. Biophys. Acta 1361 (1997) 11-19.

[22] M.D. Gorrell, V. Gysbers and G.W. McCaughan, CD26: a multifunctional integral membrane and secreted protein of activated lymphocytes, Scand. J. Immunol. 54 (2001) 249-264.

[23] J.E. Park, M.C. Lenter, R.N. Zimmermann, P. Garin-Chesa, L.J. Old and W.J. Rettig, Fibroblast activation protein, a dual specificity serine protease expressed in reactive human tumor stromal fibroblasts, J. Biol. Chem. 274 (1999) 36505-36512.

[24] F. Bermpohl, K. Loster, W. Reutter and O. Baum, Rat dipeptidyl peptidase IV (DPP IV) exhibits endopeptidase activity with specificity for denatured fibrillar collagens, FEBS Letters 428 (1998) 152-156.

[25] P.J. Collins, G. McMahon, P. O'Brien and B. O'Connor, Purification, identification and characterisation of seprase from bovine serum, Int. J. Biochem. Cell Biol. 36 (2004) 2320-2333.

[26] K.N. Lee, K.W. Jackson, V.J. Christiansen, C.S. Lee, J.G. Chun and P.A. McKee, Antiplasmin-cleaving enzyme is a soluble form of fibroblast activation protein, Blood 107 (2006) 1397-1404.

[27] K. Aertgeerts, I. Levin, L. Shi, G.P. Snell, A. Jennings, G.S. Prasad, Y. Zhang, M.L. Kraus, S. Salakian, V. Sridhar, R. Wijnands and M.G. Tennant, Structural and kinetic analysis of the substrate specificity of human fibroblast activation protein alpha, J. Biol. Chem. 280 (2005) 19441-19444.

[28] D. Ollis, E. Cheah, M. Cygler, B. Dijkstra, F. Frolow, S. Franken, M. Harel, J. Remington, I. Silman, J. Schrag, J. Sussman, K. Verschueren and A. 
Goldman, The alpha/beta hydrolase domain, Protein Engineering 5 (1992) 197-211.

[29] J.D. Cheng, R.L. Dunbrack, Jr., M. Valianou, A. Rogatko, R.K. Alpaugh and L.M. Weiner, Promotion of tumor growth by murine fibroblast activation protein, a serine protease, in an animal model, Cancer Res. 62 (2002) 47674772.

[30] V. Fulop, Z. Bocskei and L. Polgar, Prolyl Oligopeptidase: An unusual betapropeller domain regulates proteolysis, Cell 94 (1998) 161-170.

[31] M. Oertel, R. Rosencrantz, Y.-Q. Chen, P.N. Thota, J.S. Sandhu, M.D. Dabeva, A.L. Pacchia, M.E. Adelson, J.P. Dougherty and D.A. Shafritz, Repopulation of rat liver by fetal hepatoblasts and adult hepatocytes transduced ex vivo with lentiviral vectors, Hepatology 37 (2003) 994-1005.

[32] J. Niedermeyer, B. Enenkel, J.E. Park, M. Lenter, W.J. Rettig, K. Damm and A. Schnapp, Mouse fibroblast-activation protein--conserved Fap gene organization and biochemical function as a serine protease, Eur. J. Biochem. 254 (1998) 650-654.

[33] D.D. Brown, Z. Wang, J.D. Furlow, A. Kanamori, R.A. Schwartzman, B.F. Remo and A. Pinder, The thyroid hormone-induced tail resorption program during Xenopus laevis metamorphosis, Proc. Natl. Acad. Sci. U.S.A. 93 (1996) 1924-1929.

[34] J. Niedermeyer, M.J. Scanlan, P. Garin-Chesa, C. Daiber, H.H. Fiebig, L.J. Old, W.J. Rettig and A. Schnapp, Mouse fibroblast activation protein: molecular cloning, alternative splicing and expression in the reactive stroma of epithelial cancers, Int. J. Cancer 71 (1997) 383-389. 
[35] L.A. Goldstein and W.T. Chen, Identification of an alternatively spliced seprase mRNA that encodes a novel intracellular isoform, J. Biol. Chem. 275 (2000) 2554-2559.

[36] C.A. Abbott, G.W. McCaughan and M.D. Gorrell, Two highly conserved glutamic acid residues in the predicted [beta] propeller domain of dipeptidyl peptidase IV are required for its enzyme activity, FEBS Letters 458 (1999) 278-284.

[37] I. Schechter and A. Berger, On the size of the active site in proteases. I. Papain, Biochem. Biophys. Res. Commun. 27 (1967) 157-162.

[38] A.L. Fink. in: Page, M.I. and Williams, A., (Eds). Enzyme Mechanisms, Enzyme Mechanisms, Royal Society of Chemistry 1987, pp. 159-177.

[39] D. Rennex, B.A. Hemmings, J. Hofsteenge and S.R. Stone, cDNA cloning of porcine brain prolyl endopeptidase and identification of the active-site seryl residue, Biochemistry 30 (1991) 2195-2203.

[40] S. Sun, C.F. Albright, B.H. Fish, H.J. George, B.H. Selling, G.F. Hollis and R. Wynn, Expression, Purification, and Kinetic Characterization of Full-Length Human Fibroblast Activation Protein, Protein Expression and Purification 24 (2002) 274-281.

[41] Y.A. Birney and B.F. O'Connor, Purification and characterization of a Z-proprolinal-insensitive Z-Gly-Pro-7-amino-4-methyl coumarin-hydrolyzing peptidase from bovine serum--a new proline-specific peptidase, Protein Expr. Purif. 22 (2001) 286-298.

[42] D. Chen, A. Kennedy, J.Y. Wang, W. Zeng, Q. Zhao, M. Pearl, M. Zhang, Z. Suo, J.M. Nesland, Y. Qiao, A.K. Ng, N. Hirashima, T. Yamane, Y. Mori, M. 
Mitsumata, G. Ghersi and W.T. Chen, Activation of EDTA-resistant gelatinases in malignant human tumors, Cancer Res. 66 (2006) 9977-9985.

[43] T. Kelly, Evaluation of seprase activity, Clin. Exp. Metastasis 17 (1999) 5762.

[44] C.A. Abbott, D. Koorey and G.W. McCaughan, An EcoRI polymorphism within the dipeptidyl peptidase IV (DPPIV) gene, Hum. Mol. Genet. 2 (1993) 1507.

[45] G. Ghersi, H. Dong, L.A. Goldstein, Y. Yeh, L. Hakkinen, H.S. Larjava and W.T. Chen, Regulation of fibroblast migration on collagenous matrix by a cell surface peptidase complex, J. Biol. Chem. 277 (2002) 29231-29241.

[46] W.J. Rettig, P. Garin-Chesa, H.R. Beresford, H.F. Oettgen, M.R. Melamed and L.J. Old, Cell-surface glycoproteins of human sarcomas: differential expression in normal and malignant tissues and cultured cells, Proc. Natl. Acad. Sci. U.S.A. 85 (1988) 3110-3114.

[47] H. Dolznig, N. Schweifer, C. Puri, N. Kraut, W.J. Rettig, D. Kerjaschki and P. Garin-Chesa, Characterization of cancer stroma markers: in silico analysis of an mRNA expression database for fibroblast activation protein and endosialin, Cancer Immun. 5 (2005) 10.

[48] N. Ariga, E. Sato, N. Ohuchi, H. Nagura and H. Ohtani, Stromal expression of fibroblast activation protein/seprase, a cell membrane serine proteinase and gelatinase, is associated with longer survival in patients with invasive ductal carcinoma of breast, Int. J. Cancer 95 (2001) 67-72.

[49] T. Kelly, S. Kechelava, T.L. Rozypal, K.W. West and S. Korourian, Seprase, a membrane-bound protease, is overexpressed by invasive ductal carcinoma cells of human breast cancers, Mod. Pathol. 11 (1998) 855-863. 
[50] X. Jin, S. Iwasa, K. Okada, M. Mitsumata and A. Ooi, Expression patterns of seprase, a membrane serine protease, in cervical carcinoma and cervical intraepithelial neoplasm, Anticancer Res. 23 (2003) 3195-3198.

[51] K. Okada, W.T. Chen, S. Iwasa, X. Jin, T. Yamane, A. Ooi and M. Mitsumata, Seprase, a membrane-type serine protease, has different expression patterns in intestinal- and diffuse-type gastric cancer, Oncology 65 (2003) 363-370.

[52] M.Z. Zhang, Y.H. Qiao, J.M. Nesland and Z.H. Suo, Expression of seprase in effusions from patients with epithelial ovarian carcinoma, Chin. Med. J. (Engl) 120 (2007) 663-668.

[53] Y. Mori, K. Kono, Y. Matsumoto, H. Fujii, T. Yamane, M. Mitsumata and W.T. Chen, The expression of a type II transmembrane serine protease (Seprase) in human gastric carcinoma, Oncology 67 (2004) 411-419.

[54] P.S. Acharya, A. Zukas, V. Chandan, A.L. Katzenstein and E. Pure, Fibroblast activation protein: a serine protease expressed at the remodeling interface in idiopathic pulmonary fibrosis, Hum. Pathol. 37 (2006) 352-360.

[55] J.M. Milner, L. Kevorkian, D.A. Young, D. Jones, R. Wait, S.T. Donell, E. Barksby, A.M. Patterson, J. Middleton, B.F. Cravatt, I.M. Clark, A.D. Rowan and T.E. Cawston, Fibroblast activation protein alpha is expressed by chondrocytes following a pro-inflammatory stimulus and is elevated in osteoarthritis, Arthritis Res. Ther. 8 (2006) R23.

[56] S.M. Ibrahim, D. Koczan and H.J. Thiesen, Gene-expression profile of collagen-induced arthritis, J. Autoimmun. 18 (2002) 159-167.

[57] M.A. Huber, N. Kraut, J.E. Park, R.D. Schubert, W.J. Rettig, R.U. Peter and P. Garin-Chesa, Fibroblast activation protein: differential expression and serine 
protease activity in reactive stromal fibroblasts of melanocytic skin tumors, J. Invest. Dermatol. 120 (2003) 182-188.

[58] M.A. Huber, N. Kraut, N. Schweifer, H. Dolznig, R.U. Peter, R.D. Schubert, K. Scharffetter-Kochanek, H. Pehamberger and P. Garin-Chesa, Expression of stromal cell markers in distinct compartments of human skin cancers, J. Cutan. Pathol. 33 (2006) 145-155.

[59] K.M. Skubitz and A.P.N. Skubitz, Gene expression in aggressive fibromatosis, Journal of Laboratory and Clinical Medicine 143 (2004) 89-98.

[60] M.T. Levy, G.W. McCaughan, C.A. Abbott, J.E. Park, A.M. Cunningham, E. Muller, W.J. Rettig and M.D. Gorrell, Fibroblast activation protein: a cell surface dipeptidyl peptidase and gelatinase expressed by stellate cells at the tissue remodelling interface in human cirrhosis, Hepatology 29 (1999) 17681778.

[61] M.T. Levy, G.W. McCaughan, G. Marinos and M.D. Gorrell, Chronic hepatitis C: Hepatic expression of fibroblast activation protein correlates with hepatic fibrosis., Hepatology 30 (1999) 323A-323A.

[62] R. Alcolado, M.J. Arthur and J.P. Iredale, Pathogenesis of liver fibrosis, Clin. Sci. (Lond.) 92 (1997) 103-112.

[63] M.T. Levy, G.W. McCaughan, G. Marinos and M.D. Gorrell, Intrahepatic expression of the hepatic stellate cell marker fibroblast activation protein correlates with the degree of fibrosis in hepatitis $\mathrm{C}$ virus infection, Liver 22 (2002) 93-101.

[64] J. Niedermeyer, P. Garin-Chesa, M. Kriz, F. Hilberg, E. Mueller, U. Bamberger, W.J. Rettig and A. Schnapp, Expression of the fibroblast 
activation protein during mouse embryo development, Int. J. Dev. Biol. 45 (2001) 445-447.

[65] S. Welt, C.R. Divgi, A.M. Scott, P. Garin-Chesa, R.D. Finn, M. Graham, E.A. Carswell, A. Cohen, S.M. Larson, L.J. Old and et al., Antibody targeting in metastatic colon cancer: a phase I study of monoclonal antibody F19 against a cell-surface protein of reactive tumor stromal fibroblasts, J. Clin. Oncol. 12 (1994) 1193-1203.

[66] T. Kelly, S.C. Mueller, Y. Yeh and W.T. Chen, Invadopodia promote proteolysis of a wide variety of extracellular matrix proteins, J. Cell Physiol. 158 (1994) 299-308.

[67] T. Ramirez-Montagut, N.E. Blachere, E.V. Sviderskaya, D.C. Bennett, W.J. Rettig, P. Garin-Chesa and A.N. Houghton, FAPalpha, a surface peptidase expressed during wound healing, is a tumor suppressor, Oncogene 23 (2004) $5435-5446$

[68] S. Welt and G. Ritter, Antibodies in the therapy of colon cancer, Seminars in Oncology 26 (1999) 683-690.

[69] U.V. Wesley, A.P. Albino, S. Tiwari and A.N. Houghton, A role for dipeptidyl peptidase IV in suppressing the malignant phenotype of melanocytic cells, Journal of Experimental Medicine 190 (1999) 311-322.

[70] J.D. Goodman, T.L. Rozypal and T. Kelly, Seprase, a membrane-bound protease, alleviates the serum growth requirement of human breast cancer cells, Clin. Exp. Metastasis 20 (2003) 459-470.

[71] R.W. Ruddon. Oxford Univ. Press, New York 1987, pp. 190-296. 
[72] Y. Huang, S. Wang and T. Kelly, Seprase promotes rapid tumor growth and increased microvessel density in a mouse model of human breast cancer, Cancer Res. 64 (2004) 2712-2716.

[73] R.T. Aimes, A. Zijlstra, J.D. Hooper, S.M. Ogbourne, M.L. Sit, S. Fuchs, D.C. Gotley, J.P. Quigley and T.M. Antalis, Endothelial cell serine proteases expressed during vascular morphogenesis and angiogenesis, Thrombosis and Haemostasis 89 (2003) 561-572.

[74] X.M. Wang, D.M.T. Yu, G.W. McCaughan and M.D. Gorrell, Fibroblast activation protein increases apoptosis, cell adhesion, and migration by the LX2 human stellate cell line, Hepatology 42 (2005) 935-945.

[75] X.M. Wang, D.M. Yu, A. Schnapp, D. Marguet, S. Cordoba, W. Rettig, G.W. McCaughan and M.D. Gorrell, The role of fibroblast activation protein (FAP) in cell adhesion, migration and liver fibrosis, Hepatology 42 (2005) 738A738A.

[76] J. Stremenova, E. Krepela, V. Mares, J. Trim, V. Dbaly, J. Marek, Z. Vanickova, V. Lisa, C. Yea and A. Sedo, Expression and enzymatic activity of dipeptidyl peptidase-IV in human astrocytic tumours are associated with tumour grade, Int. J. Oncol. 31 (2007) 785-792.

[77] T. Kelly, Fibroblast activation protein-[alpha] and dipeptidyl peptidase IV (CD26): Cell-surface proteases that activate cell signaling and are potential targets for cancer therapy, Drug Resistance Updates 8 (2005) 51-58.

[78] V.V. Artym, A.L. Kindzelskii, W.T. Chen and H.R. Petty, Molecular proximity of seprase and the urokinase-type plasminogen activator receptor on malignant melanoma cell membranes: dependence on beta1 integrins and the cytoskeleton, Carcinogenesis 23 (2002) 1593-1601. 
[79] S.C. Mueller, G. Ghersi, S.K. Akiyama, Q.X. Sang, L. Howard, M. PineiroSanchez, H. Nakahara, Y. Yeh and W.T. Chen, A novel protease-docking function of integrin at invadopodia, J. Biol. Chem. 274 (1999) 24947-24952.

[80] G. Ghersi, H. Dong, L.A. Goldstein, Y. Yeh, L. Hakkinen, H.S. Larjava and W.T. Chen, Seprase-dPPIV association and prolyl peptidase and gelatinase activities of the protease complex, Adv. Exp. Med. Biol. 524 (2003) 87-94.

[81] G. Ghersi, Q. Zhao, M. Salamone, Y. Yeh, S. Zucker and W.T. Chen, The protease complex consisting of dipeptidyl peptidase IV and seprase plays a role in the migration and invasion of human endothelial cells in collagenous matrices, Cancer Res. 66 (2006) 4652-4661.

[82] K.N. Lee, K.W. Jackson, V.J. Christiansen, C.S. Lee, J.G. Chun and P.A. McKee, Antiplasmin-cleaving enzyme is a soluble form of fibroblast activation protein, Blood (2005).

[83] S.C. Lee, K.N. Lee, D.G. Schwartzott, K.W. Jackson, W.C. Tae and P.A. McKee, Purification of human alpha 2-antiplasmin with chicken IgY specific to its carboxy-terminal peptide, Prep. Biochem. Biotechnol. 27 (1997) 227237.

[84] K. Bangert, A.H. Johnsen, U. Christensen and S. Thorsen, Different Nterminal forms of alpha 2-plasmin inhibitor in human plasma, Biochem. J. 291 (Pt 2) (1993) 623-625.

[85] K.N. Lee, K.W. Jackson, V.J. Christiansen, K.H. Chung and P.A. McKee, A novel plasma proteinase potentiates alpha(2)-antiplasmin inhibition of fibrin digestion, Blood 103 (2004) 3783-3788.

[86] T. Koyama, Y. Koike, S. Toyota, F. Miyagi, N. Suzuki and N. Aoki, Different NH2-terminal form with 12 additional residues of alpha 2-plasmin inhibitor 
from human plasma and culture media of Hep G2 cells, Biochem. Biophys. Res. Commun. 200 (1994) 417-422.

[87] M. Del Rosso, G. Fibbi, M. Pucci, S. D'Alessio, A. Del Rosso, L. Magnelli and V. Chiarugi, Multiple pathways of cell invasion are regulated by multiple families of serine proteases, Clin. Exp. Metastasis 19 (2002) 193-207.

[88] K. Okada, S. Ueshima, M. Imano, K. Kataoka and O. Matsuo, The regulation of liver regeneration by the plasmin/alpha 2-antiplasmin system, J. Hepatol. 40 (2004) 110-116.

[89] C. Gerner, W. Steinkellner, K. Holzmann, A. Gsur, R. Grimm, C. Ensinger, P. Obrist and G. Sauermann, Elevated plasma levels of crosslinked fibrinogen gamma-chain dimer indicate cancer-related fibrin deposition and fibrinolysis, Thromb. Haemost. 85 (2001) 494-501.

[90] J.A. Garcia-Horsman, P.T. Mannisto and J.I. Venalainen, On the role of prolyl oligopeptidase in health and disease, Neuropeptides 41 (2007) 1-24.

[91] J.D. Cheng, M. Valianou, A.A. Canutescu, E.K. Jaffe, H.O. Lee, H. Wang, J.H. Lai, W.W. Bachovchin and L.M. Weiner, Abrogation of fibroblast activation protein enzymatic activity attenuates tumor growth, Mol. Cancer. Ther. 4 (2005) 351-360.

[92] V.J. Christiansen, K.W. Jackson, K.N. Lee and P.A. McKee, Effect of fibroblast activation protein and alpha2-antiplasmin cleaving enzyme on collagen types I, III, and IV, Arch. Biochem. Biophys. 457 (2007) 177-186.

[93] C.Y. Edosada, C. Quan, T. Tran, V. Pham, C. Wiesmann, W. Fairbrother and B.B. Wolf, Peptide substrate profiling defines fibroblast activation protein as an endopeptidase of strict Gly(2)-Pro(1)-cleaving specificity, FEBS Letters $580(2006) 1581-1586$. 
[94] C.Y. Edosada, C. Quan, C. Wiesmann, T. Tran, D. Sutherlin, M. Reynolds, J.M. Elliott, H. Raab, W. Fairbrother and B.B. Wolf, Selective inhibition of fibroblast activation protein protease based on dipeptide substrate specificity, J. Biol. Chem. 281 (2006) 7437-7444.

[95] I.J. Fidler, The pathogenesis of cancer metastasis: the 'seed and soil' hypothesis revisited, Nat. Rev. Cancer 3 (2003) 453-458.

[96] B.F. Gilmore, J.F. Lynas, C.J. Scott, C. McGoohan, L. Martin and B. Walker, Dipeptide proline diphenyl phosphonates are potent, irreversible inhibitors of seprase (FAPalpha), Biochem. Biophys. Res. Commun. 346 (2006) 436-446.

[97] T. Tran, C. Quan, C.Y. Edosada, M. Mayeda, C. Wiesmann, D. Sutherlin and B.B. Wolf, Synthesis and structure-activity relationship of N-acyl-Gly-, Nacyl-Sar- and N-blocked-boroPro inhibitors of FAP, DPP4, and POP, Bioorg. Med. Chem. Lett. 17 (2007) 1438-1442.

[98] G.R. Flentke, E. Munoz, B.T. Huber, A.G. Plaut, C.A. Kettner and W.W. Bachovchin, Inhibition of dipeptidyl aminopeptidase IV (DP-IV) by XaaboroPro dipeptides and use of these inhibitors to examine the role of DP-IV in T-cell function, Proc. Natl. Acad. Sci. U.S.A. 88 (1991) 1556-1559.

[99] S. Adams, G.T. Miller, M.I. Jesson, T. Watanabe, B. Jones and B.P. Wallner, PT-100, a small molecule dipeptidyl peptidase inhibitor has potent antitumor effects and augments antibody-mediated cytotoxicity via a novel immune mechanism, Cancer Research 64 (2004) 5471-5480.

[100] S. Adams, G.T. Miller and B. Jones, Dipeptidyl peptidase inhibitor PT-100 suppresses tumor growth in vivo and enhances chemotherapy in mice. [Abstract], Clin. Cancer. Res. 9 (2003) C109. 
[101] A.M. Scott, G. Wiseman, S. Welt, A. Adjei, F.T. Lee, W. Hopkins, C.R. Divgi, L.H. Hanson, P. Mitchell, D.N. Gansen, S.M. Larson, J.N. Ingle, E.W. Hoffman, P. Tanswell, G. Ritter, L.S. Cohen, P. Bette, L. Arvay, A. Amelsberg, D. Vlock, W.J. Rettig and L.J. Old, A Phase I dose-escalation study of sibrotuzumab in patients with advanced or metastatic fibroblast activation protein-positive cancer, Clin. Cancer Res. 9 (2003) 1639-1647.

[102] M. Mersmann, A. Schmidt, J.F. Rippmann, T. Wuest, B. Brocks, W.J. Rettig, P. Garin-Chesa, K. Pfizenmaier and D. Moosmayer, Human antibody derivatives against the fibroblast activation protein for tumor stroma targeting of carcinomas, Int. J. Cancer 92 (2001) 240-248.

[103] K. Tahtis, F.T. Lee, J.M. Wheatley, P. Garin-Chesa, J.E. Park, F.E. Smyth, Y. Obata, E. Stockert, C.M. Hall, L.J. Old, W.J. Rettig and A.M. Scott, Expression and targeting of human fibroblast activation protein in a human skin/severe combined immunodeficient mouse breast cancer xenograft model, Mol. Cancer Ther. 2 (2003) 729-737.

[104] D. Samel, D. Muller, J. Gerspach, C. Assohou-Luty, G. Sass, G. Tiegs, K. Pfizenmaier and H. Wajant, Generation of a FasL-based proapoptotic fusion protein devoid of systemic toxicity due to cell-surface antigen-restricted Activation, J. Biol. Chem. 278 (2003) 32077-32082.

[105] R.D. Hofheinz, S.E. al-Batran, F. Hartmann, G. Hartung, D. Jager, C. Renner, P. Tanswell, U. Kunz, A. Amelsberg, H. Kuthan and G. Stehle, Stromal antigen targeting by a humanised monoclonal antibody: an early phase II trial of sibrotuzumab in patients with metastatic colorectal cancer, Onkologie 26 (2003) 44-48. 
[106] A.M. Scott, G. Wiseman, S. Welt, F.T. Lee, W. Hopkins, P. Mitchell, A. Adjei, C.R. Divgi, S.M. Larson, E.W. Hoffman, P. Tanswell, P. Bette, D. Vlock, A. Amelsberg, W. Rettig and L.J. Old, A phase I dose-escalation study of BIBH-1 in patients with advanced or metastatic fibroblast activation protein positive cancer., Journal of Nuclear Medicine 42 (2001) 311P-311P.

[107] C. Kloft, E.U. Graefe, P. Tanswell, A.M. Scott, R. Hofheinz, A. Amelsberg and M.O. Karlsson, Population pharmacokinetics of sibrotuzumab, a novel therapeutic monoclonal antibody, in cancer patients, Investigational New Drugs 22 (2004) 39-52.

[108] M. Fassnacht, J. Lee, C. Milazzo, D. Boczkowski, Z. Su, S. Nair and E. Gilboa, Induction of $\mathrm{CD} 4(+)$ and $\mathrm{CD} 8(+) \mathrm{T}$-cell responses to the human stromal antigen, fibroblast activation protein: implication for cancer immunotherapy, Clin. Cancer Res. 11 (2005) 5566-5571.

[109] J. Lee, M. Fassnacht, S. Nair, D. Boczkowski and E. Gilboa, Tumor immunotherapy targeting fibroblast activation protein, a product expressed in tumor-associated fibroblasts, Cancer Res. 65 (2005) 11156-11163.

[110] H.F. Dvorak, Tumors: wounds that do not heal. Similarities between tumor stroma generation and wound healing, N. Engl. J. Med. 315 (1986) 1650-1659.

[111] M. Loeffler, J.A. Kruger, A.G. Niethammer and R.A. Reisfeld, Targeting tumor-associated fibroblasts improves cancer chemotherapy by increasing intratumoral drug uptake, J. Clin. Invest. 116 (2006) 1955-1962.

[112] O. De Wever and M. Mareel, Role of tissue stroma in cancer cell invasion, J. Pathol. 200 (2003) 429-447. 
[113] N. Guex and M.C. Peitsch, SWISS-MODEL and the Swiss-PdbViewer: an environment for comparative protein modeling, Electrophoresis 18 (1997) $2714-2723$.

[114] F. Corpet, Multiple sequence alignment with hierarchical clustering, Nucleic Acids Res. 16 (1988) 10881-10890.

[115] K.B. Nicholas, H.B.J. Nicholas and D.W.I. Deerfield, GeneDoc: Analysis and Visualization of genetic variation., EMBnet News 4 (1997) 14. 


\section{Fig. 1. Summary of Intracellular Signalling}

Signalling from the normal epithelial cells to the stroma and back (black thin arrows) maintains the integrity of the epithelial tissue (thick arrow). During epithelial carcinogenesis, the signalling changes (dotted blue arrow) and this causes cancerassociated changes in the stroma. The new cross-talk (dotted black arrows) between the cancer cells and the stroma leads to invasion (thick arrow). Adapted from De Wever and Mareel [112], and used with permission.

(In Colour in print and on web)

\section{Fig. 2. Three-Dimensional Structure of Seprase}

The ribbon diagram illustrates the dimeric structure of Seprase ( $\mathrm{pdb}$ accession code 1Z68). The extracellular domain consists of 2 domains, an eight bladed $\beta$-propeller domain (indicated in blue) and an $\alpha / \beta$ hydrolase domain (indicated in green) that contains the catalytic triad. The catalytic residues are shown, catalytic Serine 624 (purple), Aspartic Acid 702 (cyan) and Histidine 734 (yellow). Generated using DeepView [113].

(In Colour in print and on web) 


\section{Fig. 3. Three dimensional Seprase Domains}

(A) The ribbon diagram illustrates the $\alpha / \beta$ hydrolase domain (residues $27-53$ and 493 760) of Seprase (pdb accession code 1Z68). The $\alpha / \beta$ hydrolase domain contains the catalytic triad. The catalytic residues are shown, catalytic Serine 624 (pink), Aspartic Acid 702 (cyan) and Histidine 734 (yellow). $\alpha$-helices are indicated in red, $\beta$-sheets are indicated in blue and the hydrogen bonds are indicated in green. (B) The ribbon diagram illustrates the eight bladed $\beta$-propeller domain (residues 54-492) of Seprase (pdb accession code 1Z68). Generated using DeepView [113].

(In Colour in print and on the web)

\section{Fig. 4. Amino acid sequence alignment of eukaryotic Seprase C-terminal}

Alignment of amino acid sequences for the C-terminal of Seprase; deduced sequences Homo sapiens (AAC51668), Mus musculus (AAH19190), Xenopus laevis (AAC59872) and the putative sequence Bos Taurus (XP_603457). Alignment was performed using MultAlin [114] and edited using GeneDoc [115]. Sequence similarity is represented by grey scaling, with black being the highest similarity. The amino acids of the catalytic triad $\left(\mathrm{Ser}^{624}, \mathrm{Asp}^{702}, \mathrm{His}^{734}\right)$ are indicated $(*)$. The serine protease consensus motif G-X$\mathrm{S}-\mathrm{X}-\mathrm{G}$ is underlined.

(In Black and White in both print and on web) 


\section{Fig. 5. Summary of Fibrinolytic System}

Plasmin is generated from plasminogen through the action of Tissue or Urokinase Plasminogen Activator (t-PA or uPA). Plasmin digests Fibrin giving rise to degradation products. $\alpha_{2} \mathrm{AP}$ PRO is processed to $\alpha_{2} \mathrm{AP}_{\mathrm{ACT}}$ by the action of APCE. $\alpha_{2} \mathrm{AP}_{\mathrm{ACT}}$ can crosslink with both Plasmin and Fibrin. During clot formation, $\alpha_{2} \mathrm{AP}_{\mathrm{ACT}}$ becomes cross-linked to fibrin, where it retains the ability to effectively inhibit plasmin and protect fibrin from proteolysis.

(In Black and white in both print and on web)

\section{Fig. 6. Seprase binding model}

The model shows a peptide with the $\mathrm{P}_{3}-\mathrm{P}_{1}$ ' sequence Ser-D-Ala-Pro-Ile bound to Seprase. The surface depicts the structure of Seprase (pdb accession code 1Z68) with carbon atoms shown in white, oxygens in red, and nitrogens in blue. The carbon atoms of the peptide are in yellow and the side chain of the $\mathrm{P}_{2} \mathrm{D}$-Ala residue is highlighted in cyan. This figure is taken from ref [92] and used with permission.

(In Colour in print and on the web) 